\title{
Day of the Week and Weekend Effects in the Indian Stock Market
}

\author{
Rashmi Ranjan Paital' ${ }^{1}$, Ajaya Kumar Panda ${ }^{2}$ \\ ${ }^{1}$ Economics Area, IBS Hyderabad (A Constituent of ICFAI Foundation for Higher Education), Hyderabad, India \\ ${ }^{2}$ Accounting and Finance Area, National Institute of Industrial Engineering (NITIE), Mumbai, India \\ Email: paital.rashmi@ibsindia.org, ajayapanda80@gmail.com
}

How to cite this paper: Paital, R.R. and Panda, A.K. (2018) Day of the Week and Weekend Effects in the Indian Stock Market. Theoretical Economics Letters, 8, 25592568.

https://doi.org/10.4236/tel.2018.811164

Received: July 15, 2018

Accepted: August 21, 2018

Published: August 24, 2018

Copyright ( 92018 by authors and Scientific Research Publishing Inc. This work is licensed under the Creative Commons Attribution International License (CC BY 4.0).

http://creativecommons.org/licenses/by/4.0/

(c) (i) Open Access

\begin{abstract}
The present study has investigated the day of the week and weekend effect on index returns and it's volatility in the Indian stock market using GARCH (1, 1) for Nifty 50 , Nifty midcap 50 and Nifty smallcap 50 indices. The study period starts from $1^{\text {st }}$ April, 2005 to $29^{\text {th }}$ June, 2018. This study found a strong evidence of a positive weekend effect as well as a negative Tuesday effect across all the 3 indices. It is observed that the returns on Tuesday are lower than the returns on Monday. The study also found a positive weekend effect (except Nifty 50) as well as a negative Tuesday effect on return volatility for all these 3 indices. Like return, it is also observed that market is less volatile in Tuesday than Monday. In addition to this, the present study also revealed a negative Thursday effect on return (except Nifty 50) as well as a negative Friday effect on return for Nifty smallcap index only. It is concluded that Monday is a high risk and high return day whereas, Tuesday is a low risk and low return day in comparison to Monday. If traders can take higher risk they can earn higher return on Monday. The overall findings of the study suggest that the Indian market is not efficient and market can be predictable based on historical series. The findings of this study is valuable to both academicians as well as the market participants.
\end{abstract}

\section{Keywords}

Day of the Week Effect, Weekend Effect, Seasonality, Nifty 50, Nifty Midcap 50, Nifty Smallcap 50, NSE, INDIA, GARCH $(1,1)$

\section{Introduction}

Stock market is efficient when all the information including private as well as public reflects in the stock price itself so that it is impossible for any trader to 
beat the market. There are basically three forms of market efficiency i.e. strong, semi-strong and weak. Weak form of efficiency holds in the market when a trader failed to project the current price based on the information in the past price itself. This is the case when stock market follows random walk i.e. today price is equal to yesterday price and a random figure. The random number is unpredictable. But, many studies including developed, developing as well as Indian market indicated the presence of seasonality in the stock market. Seasonality in the stock market violates the weak form of efficiency. In this case market do not follow random walk and the price can be predictable based on seasonal pattern in the past series. Seasonality in the stock market denotes calendar anomalies i.e. a particular time in the day, a particular day in the week, a particular week in the month or a particular month in the year, and the average return is significantly higher/lower in comparison to remaining period. Day of the week effect represents a particular day in the week stock return is higher/lower in comparison to other days of the week. Similarly weekend effect represents higher/lower return in Monday in comparison to remaining four trading days due to weekend effect.

The study on the seasonality in the stock market came in to focus since 1930 when Kelly [1] identified the weekend effect in the USA market for the first time. His study found significantly higher negative return on Monday in comparison to other days of the week. Rogalski [2] found returns on Monday are comparatively lower and it is higher on Friday for Canada and USA. Feng [3] found significant negative Tuesday and positive Friday effects for China. Yunita and Martain [4] found significantly higher positive return on Friday for Malaysia and Indonesia except Singapore. Derbali and Hallara [5] found significant negative Tuesday effect on return for Tunisian stock market. Gbeda and Peprah [6] found evidence of significant Friday effects on return for Nairobi Stock Exchange. Studies such as: Gregoriou et al. [7] in UK and Aly et al. [8] in Egypt, Mbululu and Chipeta [9] in Australia and Gbeda and Peprah [6] in Ghana reported no evidence of day and weekend effects in their respective markets. Interms of volatility, Kiymaz and Berument [10] found Monday is highly volatile day for Japan and Germany, Thursday for UK and Friday for USA and Canada. Derbali and Hallara [5] found significant negative Tuesday effect on return volatility for Tunisian stock market. Gbeda and Peprah [6] reported no evidence of day and week effects on return volatility for Ghana and Nairobi Stock markets.

In the case of Indian stock market, Choudhry [11] found a positive Friday effect on return for BSE 100. Bhattacharya et al. [12] found a significant positive Monday effect for BSE 100. Raj and Kumari [13] found a significant positive return on Monday and negative return on Tuesday for BSE Sensex and Nifty 50 as well. Gupta [14] showed the returns on Friday are higher in comparison to other trading days for BSE 100 and S \& P CNX 500. Chia and Liew [15] found significant positive Monday effect and negative Friday effect for BSE. Kutchu [16] reported returns are highest on Friday for S\&P CNX Nifty 50, Nifty Junior and 
CNX Nifty 500. Srinivasan and Kalaivani [17] found average returns on Monday are significantly higher than Wednesday for Nifty 50 and BSE Sensex as well. They also found a negative Tuesday effect on return volatility. Aziz and Ansari [18] found a positive Monday and Wednesday effect on return for BSE Sensex and Nifty 50 respectively. In addition they also found a negative Tuesday effect on return volatility only for BSE Sensex. Studies like: Nageswari et al. [19] in Nifty 50 and Nifty 500, Patel and Patel [20] in BSE and Mitra [21] in BSE Sensex and NSE Nifty are reported no significant evidence of day and weekend effects in the Indian stock market. Whereas, Mitra [21] additionally found statistically significant volatility on Tuesday for BSE Sensex and NSE Nifty.

Past studies in Indian stock market are mainly focused on large cap indices and stocks. Even though there is a substantial studies in Indian stock market and many of them have reported the presence of day of the week and weekend effects still it is unclear about the degree and direction of the effect for each day. Based on the past studies the primary objective of this study is to investigate the day of the week and weekend effects for Nifty 50 large cap index, Nifty 50 midcap index and Nifty 50 smallcap index. The present study has given equal importance to large cap, midcap and smallcap indices to find out a clear picture in Indian market.

\section{Data}

This study has been empirically investigated by using closing daily data for CNX Nifty 50 large cap, CNX Nifty 50 midcap and CNX nifty 50 smallcap index starting from $1^{\text {st }}$ April, 2005 to $29^{\text {th }}$ June, 2018. Our study period starts from $1^{\text {st }}$ April, 2005 due to CNX nifty smallcap index initiated from that period onwards. The total number of observations included in the study are 3272 for all these 3 indices. All the data are obtained electronically from https://www.nseindia.com/ [22]. The daily closing price of each index has been considered for this study.

The logarithmic percentage index return is calculated as follows:

$$
R_{t}=\ln \left(\frac{\text { Price }_{t}}{\text { Price }_{t-1}}\right) * 100
$$

where, $R_{t}$ stands for index return at time $t, \ln$ is natural logarithm, Price ${ }_{t-1}$ and Price $_{t}$ are two consecutive daily closing prices.

\section{Methodology}

A dummy variable regression model is fitted to examine the days of the week and weekend effect as follows:

$$
R_{t}=\alpha_{1}+\beta_{1} D_{1 t}(\text { Tue })+\beta_{2} D_{2 t}(\text { Wed })+\beta_{3} D_{3 t}(\text { Thu })+\beta_{4} D_{4 t}(\text { Fri })+\varepsilon_{t}
$$

where, $R_{t}$ represents index return at time $t . D_{1 t}, D_{2 t}, D_{3 t}$ and $D_{4 t}$ are the dummies for Tuesday, Wednesday, Thursday and Friday respectively which are defined in the following Table 1.

To avoid the dummy variable trap in the model we have excluded the Monday's 
Table 1. Variable descriptions.

\begin{tabular}{cc}
\hline Dummy Variables & Descriptions of the Variables \\
\hline$D_{1 t}$ & $D_{1 t}=1$ if it is Tuesday and 0 otherwise \\
$D_{2 t}$ & $D_{2 t}=1$ if it is Wednesday and 0 otherwise \\
$D_{3 t}$ & $D_{3 t}=1$ if it is Thursday and 0 otherwise \\
$D_{3 t}$ & $D_{3 t}=1$ if it is Friday and 0 otherwise \\
\hline
\end{tabular}

dummy in the equation. Here the coefficient $\alpha_{1}$ represents the average return on Monday. Whereas, the coefficient $\beta_{1}$ to $\beta_{4}$ values show the shifts in the average returns from the benchmark day Monday here. A statistically significant $\alpha_{1}$ confirms the presence of weekend effect in the market. Similarly a statistically significant values of $\beta_{i}$ (where, $i=1,2,3 \& 4$ ) confirms the presence of weekdays effect in the market. A statistically significant negative/positive $\beta_{1}$ indicates that the average return on Tuesday is lower/higher than the average return on Monday. In similar way we can interpret the remaining days as well.

In the financial time series data, there is a high chance to face autocorrelation as well as heteroscedasticity problems in the simple regression model. The autocorrelation and heteroscedasticity problems are detected through DW \& ARCH-LM statistics respectively. To overcome these problems, we analyzed the day of the week and weekend effect through Generalized Autoregressive Conditional Heteroscedasticity GARCH $(1,1)$ model. The conditional mean equation takes care of autocorrelation issues in the error term and the conditional variance equation takes care of heteroscedasticity issues in the error variance. The conditional mean and variance equation are expressed as follows:

\subsection{Conditional Mean Equation}

$$
R_{t}=\alpha_{1}+\psi_{1} R_{t-1}+\beta_{1} D_{1 t} \text { (Tue) }+\beta_{2} D_{2 t}(\text { Wed })+\beta_{3} D_{3 t}(\text { Thu })+\beta_{4} D_{4 t}(\text { Fri })+\varepsilon_{t}(2)
$$

Here, the conditional mean equation is an extension to the dummy variable regression Equation (1) by including an autoregressive term of the return series i.e. $R_{t-1}$. The number of autoregressive terms are selected based on minimum AIC \& SC criteria. Here the intercept coefficient $\alpha_{1}$ measures the degree and direction of weekend effect i.e. Monday effect on index return and the coefficients $\beta_{1}$ to $\beta_{4}$ measures the degree and direction of week days effect i.e. Tuesday, Wednesday, Thursday and Friday on index rerun respectively.

The error term is assumed to be normally distributed with zero mean and constant variance

$$
\varepsilon_{t} \sim\left(0, h_{t}\right)
$$

\subsection{Conditional Variance Equation}

$$
h_{t}=\delta_{1}+\lambda_{1} \varepsilon_{t-1}^{2}+\lambda_{2} h_{t-1}+\gamma_{1} D_{1 t}(\text { Tue })+\gamma_{2} D_{2 t}(\text { Wed })+\gamma_{3} D_{3 t}(\text { Thu })+\gamma_{4} D_{4 t}(\text { Fri }) \text { (3) }
$$

where, $h_{t}$ is the conditional variance of $\varepsilon_{t}$ at time $t . \delta_{1}$ is a constant term, 
$\lambda_{1}$ is the $\mathrm{ARCH}$ coefficient which reflects the influence of past squared residuals i.e. $\varepsilon_{t-1}^{2}$ on current volatility and $\lambda_{2}$ is the GARCH coefficient which reflects the influence of previous period's volatility on current volatility. Here, $\lambda_{1}$, $\lambda_{2}>0$ and sum of $\lambda_{1}+\lambda_{2} \leq 1$. In the conditional variance equation we also included dummies of Tuesday $\left(D_{1 t}\right)$, Wednesday $\left(D_{2 t}\right)$, Thursday $\left(D_{3 t}\right)$ and Friday $\left(D_{4 t}\right)$ to check the degree and direction of week days effect on stock return volatility. Like mean equation, the coefficient $\delta_{1}$ measures the degree and direction of weekend effect i.e. Monday effect on index return volatility and the coefficients $\gamma_{1}$ to $\gamma_{4}$ measure the degree and direction of week days effect i.e. Tuesday, Wednesday, Thursday and Friday on index rerun volatility respectively.

\section{Empirical Results}

Before conducting any time series analysis it is important to check the stationary properties of the series. The stationarity of the each index series are checked by Dickey Fuller (DF), Augmented Dickey Fuller (ADF) and Phillips Peron (PP) unit root tests. The unit root test results of DF, ADF and PP are reported in Table 2. The DF, ADF and PP statistics are highly significant at $1 \%$ level suggesting that all the three index return series i.e. Nifty 50, Nifty midcap 50 and Nifty smallcap 50 are stationary and can be useful for further time series analysis.

The results based on the dummy variable regression model are reported in Tables 3-5 respectively for Nifty 50 , Nifty midcap 50 and nifty smallcap 50 . The reported DW and ARCH-LM test statistics confirm the presence of autocorrelation as well as serious heteroscedasticity problems in the model. To overcome these two issues our study switched to GARCH $(1,1)$ model and the results are reported in Tables 6-8 respectively for Nifty 50, Nifty midcap 50 and Nifty small cap 50. The upper and lower panel of the table represents conditional mean and variance respectively.

Table 2. Unit root test results.

\begin{tabular}{cccc}
\hline Constraint & DF & ADF & PP \\
\hline & Levels & Levels & Levels \\
\hline Intercept & CNX Nifty 50 Return Series & \\
Intercept and Trend & $-52.372^{*}$ & $-53.8537^{*}$ & $-53.8525^{*}$ \\
& $-53.070^{*}$ & $-53.8525^{*}$ & $-53.8128^{*}$ \\
Intercept & CNX Nifty Midcap 50 Return Series & \\
Intercept and Trend & $-3.71011^{*}$ & $-50.1952^{*}$ & $-50.3758^{*}$ \\
& $-6.32174^{*}$ & $-50.1875^{*}$ & $-50.3683^{*}$ \\
Intercept & CNX Nifty Smallcap 50 Return Series & \\
Intercept and Trend & $-4.60213^{*}$ & $-47.6425^{*}$ & $-48.2918^{*}$ \\
& $-7.36086^{*}$ & $-47.6387^{*}$ & $-48.2852^{*}$ \\
\hline
\end{tabular}

${ }^{\star} 1 \%$ level of significance. Source: Authors calculation based on the data obtained from https://www.nseindia.com/ [22]. 
Table 3. Nifty 50: dummy variable regression results.

\begin{tabular}{ccccc}
\hline \multicolumn{4}{c}{$R_{t}=\alpha_{1}+\beta_{1} D_{1 t}($ Tue $)+\beta_{2} D_{2 t}(\mathrm{Wed})+\beta_{3} D_{3 t}(\mathrm{Thu})+\beta_{4} D_{4 t}(\mathrm{Fri})+\varepsilon_{t}$} & $(1)$ \\
\hline Variable & Coefficients & Standard Error & t-statistics & probability \\
\hline Intercept $\left(\alpha_{1}\right)$ & 0.060679 & 0.055734 & 1.088726 & 0.2764 \\
Tuesday $\left(\beta_{1}\right)$ & -0.04244 & 0.078759 & -0.53881 & 0.5901 \\
Wednesday $\left(\beta_{2}\right)$ & 0.02326 & 0.07867 & 0.295669 & 0.7675 \\
Thursday $\left(\beta_{3}\right)$ & -0.03467 & 0.07897 & -0.43905 & 0.6607 \\
Friday $\left(\beta_{4}\right)$ & 0.001697 & 0.079124 & 0.021442 & 0.9829 \\
\hline
\end{tabular}

R-Squared: 0.000296; D-W Stat: 1.88001; F Stat: 0.242095 (0.00); ARCH LM (5)*: 61.74189 (0.0001). ${ }^{*}$ means $1 \%$ level of significance. Source: Authors calculation based on the data obtained from https://www.nseindia.com/ [22].

Table 4. Nifty midcap 50: dummy variable regression results.

\begin{tabular}{ccccc}
\hline \multicolumn{4}{c}{$R_{t}=\alpha_{1}+\beta_{1} D_{1 t}($ Tue $)+\beta_{2} D_{2 t}(\mathrm{Wed})+\beta_{3} D_{3 t}(\mathrm{Thu})+\beta_{4} D_{4 t}(\mathrm{Fri})+\varepsilon_{t}$} & $(1)$ \\
\hline Variable & Coefficients & Standard Error & t-statistics & probability \\
\hline Intercept $\left(\alpha_{1}\right)$ & $0.121395^{\star * *}$ & 0.066744 & 1.818797 & 0.069 \\
Tuesday $\left(\beta_{1}\right)$ & -0.13318 & 0.094319 & -1.41205 & 0.158 \\
Wednesday $\left(\beta_{2}\right)$ & -0.05924 & 0.094212 & -0.62884 & 0.5295 \\
Thursday $\left(\beta_{3}\right)$ & $-0.19596^{\star *}$ & 0.094572 & -2.07211 & 0.0383 \\
Friday $\left(\beta_{4}\right)$ & -0.02018 & 0.094755 & -0.21301 & 0.8313
\end{tabular}

R-Squared: 0.001819; D-W Stat: 1.737427; F Stat: 1.488544 (0.20287); ARCH LM (5)*: 131.8347 (0.0000). ${ }^{*},{ }^{* *}$ and ${ }^{* * *}$ means significant at $1 \%, 5 \%$ and $10 \%$ levels, respectively. Source: Authors calculation based on the data obtained from https://www.nseindia.com/ [22].

Table 5. Nifty smallcap 50: dummy variable regression results.

\begin{tabular}{ccccc}
\hline \multicolumn{4}{c}{$R_{t}=\alpha_{1}+\beta_{1} D_{1 t}($ Tue $)+\beta_{2} D_{2 t}(\mathrm{Wed})+\beta_{3} D_{3 t}(\mathrm{Thu})+\beta_{4} D_{4 t}(\mathrm{Fri})+\varepsilon_{t}$} & $(1)$ \\
\hline Variable & Coefficients & Standard Error & t-statistics & probability \\
\hline Intercept $\left(\alpha_{1}\right)$ & 0.079274 & 0.066215 & 1.197225 & 0.2313 \\
Tuesday $\left(\beta_{1}\right)$ & -0.03901 & 0.093571 & -0.41689 & 0.6768 \\
Wednesday $\left(\beta_{2}\right)$ & -0.004 & 0.093465 & -0.04278 & 0.9659 \\
Thursday $\left(\beta_{3}\right)$ & -0.09417 & 0.093822 & -1.00366 & 0.3156 \\
Friday $\left(\beta_{4}\right)$ & -0.06328 & 0.094004 & -0.67321 & 0.5009 \\
\hline
\end{tabular}

R-Squared: 0.000443; D-W Stat: 1.638378; F Stat: 0.362207 (0.835644); ARCH LM (5)*: 107.7338 $(0.0000)$. ${ }^{*}$ means $1 \%$ level of significance. Source: Authors calculation based on the data obtained from https://www.nseindia.com/ [22].

Based on the minimum AIC and SC criteria, one AR term is included in the mean equation for all these three indices. The coefficient $\alpha_{1}$ is positive and statistically significant at $1 \%$ level for all these three indices indicating a positive weekend effect on return. The coefficient $\beta_{1}$ is found to be statistically significant and negative for all these three indices suggesting a negative Tuesday effect on return. And the returns on Tuesday are lower than the returns on Monday. In addition to this we also found a negative Thursday effect for nifty midcap 50 as well as nifty small cap 50 and a negative Friday effect only for Nifty smallcap 50. 
Table 6. Nifty 50: GARCH $(1,1)$ test results.

(a)

\begin{tabular}{ccccc}
\hline \multicolumn{5}{c}{ Mean Equation } \\
$R_{t}=\alpha_{1}+\psi_{1} R_{t-1}+\beta_{1} D_{1 t}($ Tue $)+\beta_{2} D_{2 t}($ Wed $)+\beta_{3} D_{3 t}($ Thu $)+\beta_{4} D_{4 t}($ Fri $)+\varepsilon_{t}$ & $(2)$ \\
\hline Variable & Coefficients & Standard Error & t-statistics & Probability \\
\hline Intercept $\left(\alpha_{1}\right)$ & $0.128865^{*}$ & 0.04047 & 3.184189 & 0.0015 \\
Tuesday $\left(\beta_{1}\right)$ & $-0.09273^{* * *}$ & 0.052624 & -1.76217 & 0.078 \\
Wednesday $\left(\beta_{2}\right)$ & -0.04791 & 0.054969 & -0.87164 & 0.3834 \\
Thursday $\left(\beta_{3}\right)$ & -0.0646 & 0.053923 & -1.19809 & 0.2309 \\
Friday $\left(\beta_{4}\right)$ & -0.05009 & 0.054691 & -0.91588 & 0.3597 \\
AR 1 $\left(\psi_{1}\right)$ & $0.067173^{*}$ & 0.019432 & 3.456897 & 0.0005 \\
\hline
\end{tabular}

(b)

\begin{tabular}{ccccc}
\hline \multicolumn{5}{c}{ Variance Equation } \\
\multicolumn{4}{c}{$h_{t}=\delta_{1}+\lambda_{1} \varepsilon_{t-1}^{2}+\lambda_{2} h_{t-1}+\gamma_{1} D_{1 t}($ Tue $)+\gamma_{2} D_{2 t}($ Wed $)+\gamma_{3} D_{3 t}($ Thu $)+\gamma_{4} D_{4 t}($ Fri $)$} & $(3)$ \\
\hline Variable & Coefficients & Standard Error & t-statistics & Probability \\
\hline Intercept $\left(\alpha_{1}\right)$ & 0.008358 & 0.042166 & 0.198204 & 0.8429 \\
Tuesday $\left(\beta_{1}\right)$ & $-0.10954^{* * *}$ & 0.065631 & -1.66906 & 0.0951 \\
Wednesday $\left(\beta_{2}\right)$ & -0.01134 & 0.062227 & -0.18218 & 0.8554 \\
Thursday $\left(\beta_{3}\right)$ & 0.050852 & 0.061135 & 0.8318 & 0.4055 \\
Friday $\left(\beta_{4}\right)$ & 0.114348 & 0.069597 & 1.643005 & 0.1004 \\
ARCH $\left(\lambda_{1}\right)$ & $0.086859^{*}$ & 0.006648 & 13.06484 & 0.0000 \\
GARCH $\left(\lambda_{2}\right)$ & $0.906259^{*}$ & 0.006742 & 134.4258 & 0.0000 \\
\hline
\end{tabular}

R-Squared: 0.003167; DW Stat: 2.011228; ARCH LM Test (5): 0.900862 (0.4794). *, ** and ${ }^{* * *}$ means significant at $1 \%, 5 \%$ and $10 \%$ levels, respectively. Source: Authors calculation based on the data obtained from https://www.nseindia.com/ [22].

Table 7. Nifty midcap 50: GARCH $(1,1)$ test results.

(a)

\begin{tabular}{|c|c|c|c|c|}
\hline \multicolumn{5}{|c|}{$\begin{array}{c}\text { Mean Equation } \\
R_{t}=\alpha_{1}+\psi_{1} R_{t-1}+\beta_{1} D_{t t}(\text { Tue })+\beta_{2} D_{2 t}(\text { Wed })+\beta_{3} D_{3 t}(\end{array}$} \\
\hline Variable & Coefficients & Standard Error & t-statistics & Probability \\
\hline Intercept $\left(\alpha_{1}\right)$ & $0.178909^{*}$ & 0.058597 & 3.053218 & 0.0023 \\
\hline Tuesday $\left(\beta_{1}\right)$ & $-0.16808^{\star *}$ & 0.071734 & -2.34313 & 0.0191 \\
\hline Wednesday $\left(\beta_{2}\right)$ & -0.10652 & 0.075993 & -1.40171 & 0.161 \\
\hline Thursday $\left(\beta_{3}\right)$ & $-0.18634^{* *}$ & 0.077414 & -2.40705 & 0.0161 \\
\hline Friday $\left(\beta_{4}\right)$ & -0.03554 & 0.073022 & -0.48667 & 0.6265 \\
\hline $\operatorname{AR} 1\left(\psi_{1}\right)$ & $0.132077^{*}$ & 0.018278 & 7.226197 & 0.0000 \\
\hline
\end{tabular}

(b)

\begin{tabular}{ccccc}
\hline \multicolumn{5}{c}{ Variance Equation } \\
$h_{t}=\delta_{1}+\lambda_{1} \varepsilon_{t-1}^{2}+\lambda_{2} h_{t-1}+\gamma_{1} D_{1 t}($ Tue $)+\gamma_{2} D_{2 t}($ Wed $)+\gamma_{3} D_{3 t}($ Thu $)+\gamma_{4} D_{4 t}($ Fri $)$ & (3) \\
\hline Variable & Coefficients & Standard Error & t-statistics & Probability \\
\hline Intercept $\left(\alpha_{1}\right)$ & $0.20478^{* *}$ & 0.089559 & 2.286523 & 0.0222 \\
\hline
\end{tabular}




\section{Continued}

\begin{tabular}{ccccc}
\hline Tuesday $\left(\beta_{1}\right)$ & $-0.52681^{*}$ & 0.138736 & -3.79725 & 0.0001 \\
Wednesday $\left(\beta_{2}\right)$ & -0.16076 & 0.123592 & -1.30073 & 0.1934 \\
Thursday $\left(\beta_{3}\right)$ & -0.02973 & 0.127714 & -0.2328 & 0.8159 \\
Friday $\left(\beta_{4}\right)$ & 0.090814 & 0.164853 & 0.550877 & 0.5817 \\
ARCH 1 $\left(\lambda_{1}\right)$ & $0.120208^{*}$ & 0.007792 & 15.42669 & 0.0000 \\
GARCH 2 $\left(\lambda_{2}\right)$ & $0.855278^{*}$ & 0.007908 & 108.1553 & 0.0000 \\
\hline
\end{tabular}

R-Squared: 0.01831; D-W Stat: 2.00300; ARCH LM Test (5): 0.84367 (0.5185). ${ }^{*},{ }^{* *}$ and ${ }^{* * *}$ means significant at $1 \%, 5 \%$ and $10 \%$ levels, respectively. Source: Authors calculation based on the data obtained from https://www.nseindia.com/ [22].

Table 8. Nifty smallcap 50: GARCH $(1,1)$ results.

(a)

\begin{tabular}{ccccc}
\hline \multicolumn{5}{c}{ Mean Equation: } \\
\multicolumn{4}{c}{$R_{t}=\alpha_{1}+\psi_{1} R_{t-1}+\beta_{1} D_{1 t}(\mathrm{Tue})+\beta_{2} D_{2 t}(\mathrm{Wed})+\beta_{3} D_{3 t}(\mathrm{Thu})+\beta_{4} D_{4 t}(\mathrm{Fri})+\varepsilon_{t}$} & $(2)$ \\
\hline Variable & Coefficients & Standard Error & t-statistics & Probability \\
\hline Intercept $\left(\alpha_{1}\right)$ & $0.174769^{*}$ & 0.055755 & 3.134604 & 0.0017 \\
Tuesday $\left(\beta_{1}\right)$ & $-0.11326^{* * *}$ & 0.067706 & -1.67276 & 0.0944 \\
Wednesday $\left(\beta_{2}\right)$ & -0.05758 & 0.074898 & -0.76872 & 0.4421 \\
Thursday $\left(\beta_{3}\right)$ & $-0.1292^{* * *}$ & 0.073804 & -1.75063 & 0.08 \\
Friday $\left(\beta_{4}\right)$ & $-0.13427^{* * *}$ & 0.069407 & -1.93456 & 0.053 \\
AR 1 $\left(\psi_{1}\right)$ & $0.180629^{*}$ & 0.018605 & 9.708784 & 0.0000 \\
\hline
\end{tabular}

(b)

\begin{tabular}{ccccc}
\hline \multicolumn{5}{c}{ Variance Equation: } \\
$h_{t}=\delta_{1}+\lambda_{1} \varepsilon_{t-1}^{2}+\lambda_{2} h_{t-1}+\gamma_{1} D_{1 t}($ Tue $)+\gamma_{2} D_{2 t}($ Wed $)+\gamma_{3} D_{3 t}($ Thu $)+\gamma_{4} D_{4 t}($ Fri $)$ & $(3)$ \\
\hline Variable & Coefficients & Standard Error & t-statistics & Probability \\
\hline Intercept $\left(\alpha_{1}\right)$ & $0.266303^{*}$ & 0.09227 & 2.886132 & 0.0039 \\
Tuesday $\left(\beta_{1}\right)$ & $-0.35892^{* *}$ & 0.139626 & -2.57059 & 0.0102 \\
Wednesday $\left(\beta_{2}\right)$ & -0.14022 & 0.12505 & -1.12134 & 0.2621 \\
Thursday $\left(\beta_{3}\right)$ & -0.165 & 0.128279 & -1.28626 & 0.1984 \\
Friday $\left(\beta_{4}\right)$ & 0.016649 & 0.162142 & 0.102681 & 0.9182 \\
ARCH 1 $\left(\lambda_{1}\right)$ & $0.150469^{*}$ & 0.009649 & 15.59424 & 0.0000 \\
GARCH 2 $\left(\lambda_{2}\right)$ & $0.803203^{*}$ & 0.010241 & 78.42955 & 0.0000 \\
\hline
\end{tabular}

R-Squared: 0.031979; D-W Stat: 2.006613; ARCH LM Test (5): 0.819698 (0.5354). ${ }^{*},{ }^{* *}$ and ${ }^{* * *}$ means significant at $1 \%, 5 \%$ and $10 \%$ levels, respectively. Source: Authors calculation based on the data obtained from https://www.nseindia.com/ [22].

In terms of volatility, the coefficient $\delta_{1}$ is found to be positive and statistically significant for Nifty midcap 50 as well as Nifty small cap 50 suggesting a positive weekend effect on return volatility. We also found a negative and statistically significant $\gamma_{1}$ for all these three indices suggesting a negative Tuesday effect on return volatility. Our results show that the market is more volatile on 
Monday than Tuesday.

Finally, the reported DW and ARCH-LM test statistics confirm that the present GARCH $(1,1)$ model is free from autocorrelation as well as heteroscedasticity problems.

\section{Conclusion}

The present study has investigated the day of the week and weekend effect on index returns and it's volatility in the Indian stock market using GARCH $(1,1)$ for Nifty 50, Nifty midcap 50 and Nifty smallcap 50 indices. The study period starts from $1^{\text {st }}$ April, 2005 to $29^{\text {th }}$ June, 2018. This study found a strong evidence of a positive weekend effect as well as a negative Tuesday effect across all the 3 indices. It is observed that the returns on Tuesday are lower than the returns on Monday. The study also found a positive weekend effect (except Nifty 50) as well as a negative Tuesday effect on return volatility for all these 3 indices. Like return, it is also observed that market is less volatile in Tuesday than Monday. In addition to this, the present study also revealed a negative Thursday effect on return (except Nifty 50) as well as a negative Friday effect on return for Nifty smallcap index only. It is concluded that Monday is a high risk and high return day whereas, Tuesday is a low risk and low return day in comparison to Monday. If traders can take higher risk they can earn higher return on Monday. The overall findings of the study suggest that the Indian market is not efficient and market can be predictable based on historical series. The findings of this study is valuable to both academicians as well as the market participants.

\section{Conflicts of Interest}

The authors declare no conflicts of interest regarding the publication of this paper.

\section{References}

[1] Kelly, F. (1930) Why You Win or Lose. The Psychology of Speculation. Houghton Mifflin, Boston.

[2] Rogalski, R.J. (1984) New Findings Regarding Day-Of-The-Week Returns over Trading and Non-Trading Periods: A Note. Journal of Finance, 39, 1603-1614. https://doi.org/10.1111/j.1540-6261.1984.tb04927.x

[3] Feng, L.C. (2000) The Day-Of-The-Week Effects in China Stock Market. Economic Research Journal, 11, 50-57.

[4] Yunita, A. and Martain, S.M. (2012) Analysis of Calendar Effects: Day-Of-TheWeek Effects in Indonesia, Singapore, and Malaysia Stock Markets. African Journal of Business Management, 11, 3880-3887. https://doi.org/10.5897/AJBM10.1038

[5] Derbali A. and Hallara. S. (2016) Day-Of-The-Week Effect on the Tunisian Stock Market Return and Volatility. Cogent Business and Management, 3.

[6] Gbeda, J.M. and Atta Peprah, J.A. (2017) Day of the Week Effect and Stock Market Volatility in Ghana and Nairobi Stock Exchanges. Journal of Economics and Finance, 1-19. https://doi.org/10.1007/s12197-017-9409-7 
[7] Gregoriou, A., Kontonikas, A. and Tsitsianis, N. (2004) Does the Day of the Week Effect Exit Once Transaction Costs Have Been Accounted for? Evidence from the UK. Applied Financial Economics, 14, 215-220. https://doi.org/10.1080/0960310042000187388

[8] Aly, H., Mehdian, S. and Perry, M. (2004) An Analysis of the Day-Of-The-Week Effects in the Egyptian Stock Market. International Journal of Business, 9, 301-308.

[9] Mbululu, D. and Chipeta, C. (2012) Day-Of-The-Week Effect: Evidence from the Nine Economic Sectors of the JSE. The Investment Analysts Journal, 41, 55-65.

[10] Kiymaz, H. and Berument, H. (2003) The Day-Of-The-Week Effect on Stock Market Volatility and Volume: International Evidence. Review of Financial Economics, 12, 363-380. https://doi.org/10.1016/S1058-3300(03)00038-7

[11] Choudhry, T. (2000) Day of the Week Effect in the Emerging Asian Markets: Evidence from the GARCH Model. Applied Financial Economics, 10, 235-242. https://doi.org/10.1080/096031000331653

[12] Bhattacharya, K., Sarkar, N. and Mukhopadhyay, D. (2003) Stability of the Day of the Week Effect in Return and in Volatility at the Indian Capital Market a GARCH Approach with Proper Mean Specification. Applied Financial Economics, 13, 553-563. https://doi.org/10.1080/0960310021000020924

[13] Raj, M. and Kumari, D. (2006) Day-Of-The-Week and Other Market Anomalies in the Indian stock Market. International Journal of Emerging Markets, 1, 235-246. https://doi.org/10.1108/17468800610674462

[14] Gupta, A. (2006) Day-Of-The-Week Effect on the Indian Stock Market: New Evidence. ICFAI Journal of Applied Finance, 12, 5-14.

[15] Chia, R.C.J. and Liew, V.K.S. (2010) Evidence on the Day-Of-The-Week Effect and Asymmetric Behavior in the Bombay Stock Exchange. The IUP Journal of Applied Finance, 16, 17-29.

[16] Kutchu, V. (2012) An Empirical Study on Day-Of-The Week Effect in Indian Stock Market during Different Settlement Regimes Using GARCH Framework. Indian Journal of Commerce \& Management Studies, 3, 85-91.

[17] Srinivasan, P. and Kalaivani, M. (2013) Day of the Week Effects in the Indian Stock Market. MPRA Paper No. 46805

[18] Aziz, T. and Ansari, V.A. (2015) The Day of the Week Effect: Evidence from India. Afro-Asian Journal of Finance and Accounting, 5, 99-112. https://doi.org/10.1504/AAJFA.2015.069886

[19] Nageswari, P., Selvam, M. and Gayathri, J. (2011) Analysis of Monday Effect in Indian Stock Market. Research Journal of Business Management, 5, 170-177. https://doi.org/10.3923/rjbm.2011.170.177

[20] Patel, R. and Patel, M. (2011) An Econometric Analysis of Bombay Stock Exchange: Annual Returns Analysis, Day of the Week Effect and Volatility of Returns. Research Journal of Finance and Accounting, 2, 1-10.

[21] Mitra, P. (2016) Day-Of-The-Week Effect on Stock Market Return and Volatility: Evidence from Indian Stock Market. IOSR Journal of Economics and Finance, 7, 99-107. https://doi.org/10.9790/5933-07040199107

[22] https://www.nseindia.com/ 